Consenso e Conflito na Lisboa do século XII

\title{
A Trasladação de S. Vicente
} Consenso e Conflito na Lisboa do século XII

Pedro Picoito

(2) OpenEdition

Journals

\section{Edição electrónica}

URL: http://journals.openedition.org/medievalista/1048

DOI: 10.4000/medievalista.1048

ISSN: 1646-740X

\section{Editora}

Instituto de Estudos Medievais - FCSH-UNL

\section{Refêrencia eletrónica}

Pedro Picoito, «A Trasladação de S. Vicente », Medievalista [Online], 4 | 2007, posto online no dia 05 março 2021, consultado o 25 março 2021. URL: http://journals.openedition.org/medievalista/1048 ; DOI: https://doi.org/10.4000/medievalista.1048

\section{(c) (7) (8)}

Mediavalista está licenciado com uma Licença Creative Commons - Atribuição-NãoComercial 4.0 Internacional. 


\title{
A Trasladação de S. Vicente Consenso e Conflito na Lisboa do século XII
}

\author{
Pedro Picoito
}

Instituto Superior de Educação e Ciências / IEM

A tradição atribui ao primeiro rei de Portugal, D. Afonso Henriques, a vinda das relíquias do popular mártir hispano-romano São Vicente de Sagres para Lisboa, em 1173. Esta trasladação teve um enorme impacto na recém-conquistada urbe da foz do Tejo, cristã desde 1147, ao ponto de o mártir valenciano suplantar por completo todos os cultos aí existentes, como São Gens, o mítico primeiro bispo lisboeta provavelmente venerado na colina com o seu nome (hoje a Graça), Santa Justa, de forte devoção entre os moçárabes, São Félix, Santo Adrião e Santa Natália, oragos do velho mosteiro de Chelas, ou os irmãos Veríssimo, Máxima e Júlia, padroeiros da ainda mais antiga igreja de Santos ${ }^{1}$.

O motivo, segundo José Mattoso, é que "a trasladação de São Vicente pode-se considerar como símbolo da cristianização definitiva da cidade" ${ }^{2}$, à imagem de acontecimentos semelhantes ocorridos durante a Reconquista ibérica: a transferência dos restos de Santo Eulógio de Córdova para Oviedo em 883, por Afonso III das Astúrias, ou de Santo Isidoro de Sevilha para Leão em 1063, por Fernando Magno.

\footnotetext{
${ }^{1}$ Aires Augusto Nascimento e Saul António Gomes, S. Vicente de Lisboa e seus milagres medievais, Lisboa, Didaskalia, 1988, pp. 8 e 9

2 José Mattoso, D. Afonso Henriques, Lisboa, Círculo de Leitores, 2006, p. 246.
} 
Em ambos os casos, um santo de grande prestígio para a Cristandade peninsular, e especialmente para os moçárabes, é levado do seu túmulo no sul islâmico para uma capital no norte cristão. Apesar de haver aqui um contexto muito próprio da Reconquista, o modelo mais antigo parece ser, no entanto, a trasladação de mártires locais dos cemitérios periféricos para as basílicas episcopais das cidades romanas no distante século IV em que o Império se converte à religião cristã $\tilde{a}^{3}$.

E assim como, nos tempos da oficialização do Cristianismo em Roma, o papel dos bispos e dos notáveis tinha sido decisivo no escolha dos novos padroeiros das capitais regionais, também o favor de S. Vicente em Lisboa se deve sobretudo ao impulso dos principais poderes políticos e religiosos da cidade, em particular a família real e a corte, embora se estenda depressa a toda a população. Em 1147, pouco depois da conquista, Afonso Henriques funda um grande mosteiro consagrado ao mártir no arrabalde oriental, sobre o cemitério de um dos exércitos de cruzados que o tinham auxiliado na conquista da cidade, entregando-o primeiro a premonstratenses flamengos e depois a cónegos regrantes vindos do norte de Portugal, de S. Salvador do Banho e de Santa Cruz de Coimbra, com o provável objectivo de evangelizar este populoso subúrbio ${ }^{4}$. Após a trasladação, as relíquias trazidas do Algarve serão depositadas no altar-mor da catedral, por expressa vontade do rei e do cabido. Em breve S. Vicente passa a ser o padroeiro da diocese e do município, como atestam um selo do cabido, de 1255, e outro do concelho, de 1233, nos quais se representam já a barca e os corvos, os tradicionais símbolos vicentinos em Portugal. A própria vereação se encarregará de organizar todos os anos, desde então, a festa da chegada das relíquias a 16 de Setembro ${ }^{5}$. E os Miracula Sancti Vincentii, o livro de milagres escrito entre 1173 e 1185 por um chantre da Sé, dão notícia do fervor de fiéis dos mais variados estratos sociais, destacando, porém, os membros do alto clero, como os cónegos da catedral lisboeta ou o Mestre dos templários portugueses ${ }^{6}$. Ou seja, a narrativa da chegada de S. Vicente a Lisboa parece

\footnotetext{
${ }^{3}$ R. A. Markus, The end of ancient christianity, Cambridge, Cambridge University Press/Canto, 1998, pp. $142-155$

4 "Indiculum Fundationis Monasterii Beati Vincentii", in Aires Nascimento (ed.), A conquista de Lisboa aos mouros, Lisboa, Vega, 2001, pp. 177-201; Carlos Guardado da Silva, O mosteiro de S. Vicente de Fora. A comunidade regrante e o património rural (Séculos XII-XIII), Lisboa, Colibri, 2002, pp. 47-50.

5 Irisalva Moita, "Introdução" in VIII Centenário da Trasladação das Relíquias de São Vicente, Lisboa, Câmara Municipal de Lisboa, 1973, pp. 27-30, 153 e 157.

${ }^{6}$ Nascimento e Gomes, S. Vicente, pp. 18-27 e 43-69.
} 
ilustrar aquele ideal de adventus e consensus que Peter Brown associa à função social das trasladações desde os primeiros séculos da Cristandade ${ }^{7}$.

No entanto, uma leitura mais atenta de tal narrativa, para além do aparente unidade em torno do novo culto, revela que o acontecimento provocou um violento conflito entre os diversos grupos que então compunham o tecido urbano de Lisboa, fazendo mesmo duvidar que a iniciativa de trazer os restos vicentinos tenha partido do soberano. É certo que, de acordo com o texto, Afonso Henriques tentara resgatar o corpo de S. Vicente antes de 1147, através de uma incursão armada (provavelmente um fossado) em território muçulmano. Mas essa iniciativa não teve êxito, diz-se expressamente, "porque a ele [S. Vicente] lhe aprouvera ser venerado de preferência pela gente de Lisboa e a intenção do rei era, pelo contrário, depositá-lo em Braga ou em Coimbra, já que a misericórdia divina ainda não lhe entregara Lisboa." ${ }^{, 8} \mathrm{O}$ que significa, portanto, que segundo o relato oficial da trasladação, o santo identifica o seu novo túmulo não com o rei ou com o reino de Portugal, mas com o povo de Lisboa.

O facto de os Miracula serem escritos por um clérigo da principal igreja da cidade poderá explicar esta forte identificação local, mas há outro aspecto a ter em conta. Mais à frente, diz-se que único resultado positivo da operação teria sido "o resgate $d a$ servidão dos infiéis para terra cristã de grande número de cristãos a quem se dá o nome de moçárabes", um facto confirmado pela coeva Vida de S. Teotónio ${ }^{9}$. Dois desses moçárabes, monges do santuário algarvio de $\mathrm{S}$. Vicente entretanto destruído pelos almorávidas, acabam por instalar-se em Lisboa, supõe-se que depois da conquista afonsina. Ora, "a muitos que ansiosamente procuravam notícias, deram eles conhecimento do lugar preciso onde, segundo lhes haviam dito os seus antecessores, fora depositado o bem-aventurado Vicente". Munidos de tão preciosa informação, e

"havendo finalmente um tratado de paz entre o rei e os mouros (...) alguns homens corajosos inspirados por Deus (...) aventuram-se ao mar, arrostam com os perigos e chegam ao lugar desejado. Entregam-se a vigílias de oração desbravam a terra em

\footnotetext{
${ }^{7}$ The cult of the saints. Its rise and function in Latin Christianity, Chicago, Univeristy of Chicago Press, 1981, pp. 90-105.

${ }^{8}$ Nascimento e Gomes, S. Vicente, p. 33.

9 Aires Nascimento (ed.), "Vita Theotonii" in Hagiografia de Santa Cruz de Coimbra, Lisboa, Colibri, 1998, p. 177.
} 
torno dos locais previamente assinalados e, depois de muito trabalho, por revelação divina, encontram o corpo tão procurado. (...) Regressam a Lisboa e entram no porto, remam para terra, e pondo aos ombros, com piedade, o corpo sacratíssimo, retiram-no do navio. Entretanto, não fosse a violência de alguns causar qualquer dano, durante a noite, quase sem deixarem entender por onde passavam, conduzem-no à igreja de Santa Justa."

Vale a pena citar tão longamente esta passagem porque ela é surpreendente. Desta vez, Afonso Henriques não aparece. A iniciativa da trasladação bem sucedida não lhe pertence. Pelo contrário, parte de alguns habitantes de Lisboa que sabem ir por mar até ao Algarve (pormenor importante porque revela familiaridade com a costa meridional), colhendo antes informações junto dos dois monges moçárabes a viver na cidade. Mais: nem o rei nem nenhum representante seu, nem mesmo o bispo ou qualquer outro dignitário eclesiástico, recebem as prestigiadas relíquias, relíquias que chegam de noite e clandestinamente, por medo da "violência de alguns".

Quem são estes "homens corajosos e inpirados por Deus" que trazem o corpo de S. Vicente? E quem são aqueles de quem temem a violência?

Embora nunca o afirme claramente, entre outras coisas porque é pouco posterior aos factos narrados e a diplomacia se impõe, o texto sugere algumas respostas.

Em primeiro lugar, note-se a proximidade entre os lisboetas e os moçárabes algarvios, uma proximidade de que o próprio rei parece estar arredado. Havia boas razões para isso. Afonso Henriques estava empenhado, desde que subira ao trono, na extensão a todo o reino da reforma gregoriana, que consistia, entre outros aspectos, na substituição da liturgia visigótica pela liturgia romana, na troca do velho monaquismo hispânico pelo de Cister e dos cónegos regrantes e, em parte, na nomeação de um novo episcopado vindo de além-Pirenéus e do norte da Península. Tratava-se de um árduo processo de aculturação destinado sobretudo a enquadrar sob um novo poder as estruturas eclesiásticas e as práticas religiosas moçárabes, enquadramento que o seu avô Afonso VI levara a cabo, com notável dificuldade, nos territórios ganhos pela Reconquista no 
século XI, particularmente em Toledo, e o seu pai, Henrique de Borgonha, intentara em Coimbra pouco depois, provocando a mesma resistência ${ }^{10}$.

Em Lisboa, Afonso Henriques nomeou para a cátedra episcopal, escassos dias após a conquista, o anglo-normando Gilberto de Hastings, não dando qualquer relevo à existência de um bispo moçárabe (aliás morto pelos cruzados) ${ }^{11}$, e instalou a nova catedral no espaço da mesquita aljama, ignorando por completo a anterior sé que, segundo Manuel Real, se situaria em Santa Maria de Alcamim ${ }^{12}$. É de assinalar que se trata de circunstâncias muito semelhantes às que viveu Toledo no pós-1085 ${ }^{13}$. Além disso, como já vimos, o rei português funda os principais templos dos arrabaldes sobre cemitérios de cruzados, o germânico a leste e o anglo-normando a oeste, respectivamente o mosteiro de $\mathrm{S}$. Vicente, próximo da mouraria e entregue a premonstratenses flamengos, e a basílica de Santa Maria dos Mártires, dominando o bairro moçárabe, onde se situam Santa Justa e Santa Maria de Alcamim, e colocada na dependência directa do bispo ${ }^{14}$.

Há, pois, um evidente aspecto de colonialismo religioso nas relações entre os conquistadores e os moçárabes, que será mesmo reforçado nas décadas seguintes com a doação a instituições monásticas protegidas pela Coroa de santuários anteriores à conquista. Casos de S. Gens, onde se instalam os eremitas de Santo Agostinho, do mosteiro de Santos, que passa para a Ordem de Santiago, ou do mosteiro de Chelas, doado aos templários, primeiro, e às dominicanas, mais tarde ${ }^{15}$. E é ainda mais significativo que Santa Maria de Alcamim se veja em breve rebaptizada com um novo

\footnotetext{
${ }^{10}$ Maria de Lurdes Rosa, "A força dos ritos na identificação comunitária: os moçárabes de Coimbra e a introdução da liturgia romana (1064-1116)" in Carlos Moreira Azevedo (dir.), História Religiosa de Portugal, vol. 1, Lisboa, Círculo de Leitores, pp. 433-440.

11 "De Expugnatione Lyxbonensi" in Nascimento, A conquista de Lisboa aos mouros, pp. 139-143.

${ }^{12}$ Segundo a hipótese de Manuel Real, "Os moçárabes do Gharb português" in Cláudio Torres e Santiago Macias (coord.), Portugal Islâmico. Os ultimos sinais do Mediterrâneo, Lisboa, Museu Nacional de Arqueologia, 1998, p. 51.

${ }^{13}$ Francisco J. Hernández, "A catedral, instrumento de assimilação", in Louis Cardaillac, (dir.), Toledo. Séculos XII-XIII. Muçulmanos, cristãos e judeus: o saber e a tolerância, Lisboa, Terramar, 1996, pp. 7086. Ver também Reyna Pastor, «Problèmes d'assimilation d'une minorité: le mozárabes de Tolède de 1085 à la fin du XIIIe siècle » in Annales E.S.C., 1970, pp. 351-390.

14 "Indiculum", in Nascimento, A Conquista de Lisboa aos mouros, pp. 190-191.

${ }^{15}$ Pedro Picoito, "O rei, o santo e a cidade. O culto de S. Vicente em Lisboa e o projecto político de Afonso Henriques" in Isabel Alçada Cardoso (coord.), São Vicente, diácono e mártir, Lisboa, Cabido da Sé de Lisboa/ Centro Cultural Pedro Hispano, 2005, pp. 71-72.
} 
orago, S. Cristóvão, num claro indício de menorização da hierarquia eclesiástica moçárabe.

No entanto, todas estas aparentes tentativas de domínio simbólico sobre os moçárabes contrastam com o visível desejo de boas relações com a comuna islâmica, materializado na concessão da carta de foral aos "mouros forros" de Lisboa, Almada, Palmela e Alcácer do Sal em 1170. Afonso Henriques estava então inválido e incapaz de combater, na sequência do acidente de guerra ocorrido em Badajoz, meses antes, e os poderosos almóadas ameaçavam o reino, que viriam a invadir no ano seguinte, chegando a cercar Santarém, a escassa meia centena de quilómetros de Lisboa. A data do foral das mourarias das quatro localidades, todas próximas e situadas nas bacias do Tejo e do Sado, indicia, portanto, uma manifestação de boa vontade do monarca para com os súbditos menos fiáveis da fronteira meridional do reino. Tanto mais que só em 1179 o próprio concelho de Lisboa receberá idêntico diploma, o que diz bem dos cuidados de Afonso Henriques com a minoria islâmica, enquadrada juridicamente antes até da maioria cristã.

Perante esta conjuntura, é tentador ver na chegada das relíquias de S. Vicente em 1173 uma tentativa de afirmação colectiva dos moçárabes lisboetas, cada vez mais marginalizados pelo poder político e religioso. $\mathrm{Na}$ típica sociedade fronteiriça e heterogénea que era então Lisboa, palco da luta pelo "reconhecimento" (na expressão de Charles Taylor ${ }^{16}$ ) de comunidades das mais diversas origens étnicas e geográficas portugueses, galegos, francos, normandos, alemães, flamengos, muçulmanos -, os moçárabes desejariam ostentar a posse de um símbolo da sua antiquíssima identidade hispano-cristã. O objectivo seria combater aquilo a que Thomas Glick chama cruamente de "irrelevância histórica" - a incapacidade de se oporem com eficácia à hegemonia cultural dos conquistadores, fossem estes cristãos do norte ou mouros do sul ${ }^{17}$. O corpo incorrupto de S. Vicente, o grande mártir da Hispânia pré-gótica e pré-islâmica, representaria assim, para os moçárabes de Lisboa no século XII, a sobrevivência colectiva do grupo contra as investidas do rei e do bispo, tal como já fizera, para os

\footnotetext{
16 "The politics of recognition" in Amy Gutmann (ed.), Multiculturalism, Princeton, Princeton University Press, 1994, pp. 25-75.

${ }^{17}$ Cristianos y musulmanes en la España medieval (711-12509), Madrid, Alianza Universidad, 1991, p. 232.
} 
moçárabes do Algarve nos tempos posteriores ao século VIII, face aos invasores muçulmanos.

Dois dos argumentos que sustentam esta tese foram já sugeridos: o facto de os habitantes de Lisboa obterem informações sobre o túmulo de S. Vicente em Sagres junto de moçárabes algarvios, e o conhecimento da costa vicentina que lhes permite fazer, sem grande dificuldade, a viagem por mar. Mas há outro argumento ainda mais forte: a deposição das relíquias na igreja de Santa Justa, aproveitando o braço do Tejo que na Idade Média subia até ao actual Rossio. Santa Justa situava-se, de acordo com o arqueólogo José Luís de Matos, no vértice ribeirinho da moçarabia. Seria, pois, uma igreja pertencente aos seus habitantes, como aliás se depreende da invocação, tradicionalmente associada aos moçárabes de toda a Península ${ }^{18}$. A chegada das relíquias a este templo, ainda por cima em segredo, faz suspeitar que os moçárabes lisboetas pretenderiam apropriar-se de um culto de enorme prestígio. Tendo em conta o seu valor, é natural que temessem a "inconsiderada violência de alguns", óbvia alusão às outras comunidades cristãs.

Com efeito, os Miracula narram seguidamente que, "ao romper da manhã, quando a ocorrência de facto tão excelso se tornou conhecida da cidade, acorreram muitos homens, uns desarmados e outros armados" "19. O segundo grupo, ameaçador, exige que S. Vicente seja levado para o mosteiro homónimo, enquanto "os outros, mais ponderadamente", querem impor como alternativa a Sé, ali bem perto. Se até aqui a narrativa se polarizara em torno da rivalidade implícita entre os moçárabes e os outros cristãos, como vimos, agora entra em jogo a rivalidade muito mais explícita entre a catedral e o mosteiro de $\mathrm{S}$. Vicente, uma rivalidade que alimentaria intermináveis disputas canónicas nos séculos seguintes ${ }^{20}$.

Recorde-se que os Miracula são escritos por Mestre Estêvão, um chantre da Sé, o que se nota no modo como atribui aos regrantes ou aos seus partidários a escalada da violência. E recorde-se também a diferente origem étnica dos dois grupos. A Sé continuava a ser regida por um bispo e vários cónegos anglo-normandos, em número suficiente para que a igreja mais próxima da catedral fosse consagrada a S. Jorge, padroeiro de Inglaterra, e

\footnotetext{
18 José Luís de Matos, Lisboa islâmica, Lisboa, Instituto Camões, 1999, pp. 31-33.

${ }^{19}$ Nascimento e Gomes, S. Vicente, p. 35-39.

${ }^{20}$ Carlos Guardado da Silva, O mosteiro de S. Vicente de Fora, pp. 74-80.
} 
o deão se chamasse Roberto, nome de ressonância nórdica ${ }^{21}$. Quanto a S. Vicente, além dos iniciais premonstratenses flamengos, entretanto desaparecidos, e dos regrantes minhotos e coimbrões, que terão chegado algures na década de 50, incluía entre os conversos alguns cruzados de língua germânica, os quais alimentaram certamente o peculiar culto de Henrique de Bona, cavaleiro morto durante o cerco de 1147 cuja memória se confunde com a da própria fundação do cenóbio ${ }^{22}$.

A disputa pelas relíquias entre os três grupos - moçárabes, cónegos da Sé e regrantes de S. Vicente - torna-se de tal modo aguda que o fronteiro da Estremadura, Gonçalo Viegas de Lanhoso, um fidalgo minhoto ${ }^{23}$, desce da alcáçova, onde muito provavelmente residia, para pôr cobro ao tumulto. "Homem valoroso e prudente", segundo os Miracula, "dá ordem para se pôr termo a discussões e se esperar pela decisão do rei sobre assunto de tamanha importância”.

Esta intervenção é extremamente reveladora.

Em primeiro lugar, porque constitui mais uma prova, e decisiva, de que não foi Afonso Henriques quem tomou a iniciativa da trasladação, pois o seu máximo representante em Lisboa evidencia ter sido completamente surpreendido pela chegada das relíquias, ao ponto de ter que aguardar instruções do soberano em plena crise. Soberano esse que, convém sublinhar, não está presente para receber o corpo de São Vicente, uma circunstância muito estranha no caso de ter sido ele a promovê-la.

Em segundo lugar, a aparição de Gonçalo Viegas faz entrar em cena um outro grupo politicamente dominante na cidade: o dos colonos do Norte de Portugal e da Galiza, que Afonso Henriques instala na zona da alcáçova e em torno da igreja de Santiago, o padroeiro da Reconquista, a fim de controlar esta importante praça fronteiriça. Gonçalo Viegas de Lanhoso, fidalgo de segunda linha da pequena nobreza do Minho, constitui um bom exemplo do tipo sociológico de funcionários militares, civis e eclesiásticos de

\footnotetext{
${ }^{21}$ Maria João Branco, "A conquista de Lisboa revisitada" in Arqueologia Medieval, 7, 2001, p. 223.

22 "Indiculum" in Nascimento, A conquista de Lisboa aos mouros, 184-189. Sobre este culto, ver Armando Pereira, "Guerra e santidade: o cavaleiro-mártir Henrique de Bona e a conquista cristã de Lisboa" in Núcleo Científico de Estudos Medievais (coord.), A nova Lisboa medieval. Actas do I Encontro, Lisboa, Colibri, 2005, pp. 51-74 . Sobre o papel mediador dos conversos entre a vida monástica e a piedade da aristocracia guerreira, ver Marcus Bull, Knightly piety and the lay Response to the first crusade. The Limousin and the Gascony (c. 970-c. 1130), Oxford, Clarendon Press, 1993, pp. 115-155.

${ }^{23}$ José Mattoso, Ricos-Homens, infanções e cavaleiros. A nobreza medieval portuguesa nos Séculos XI e XII, Lisboa, Guimarães Editores, 1982, pp. 232-235.
} 
que a Coroa portuguesa se serviria para assegurar a colonização do território conquistado, em troca de glória e fortuna. Outro exemplo mais célebre, embora talvez menos determinante, é o de Gonçalo Mendes da Maia, o famoso Lidador, fronteiro de Beja que viria a inspirar uma lenda recolhida quase dois séculos depois pelos Livros de Linhagens $^{24}$.

Contudo, nem mesmo a acção do principal poder político-militar de Lisboa consegue resolver por completo o diferendo entre os seus vários grupos étnicos. Será necessária toda a diplomacia de Roberto, o deão da Sé, "homem de Deus e benquisto pelo povo da cidade", além de "alguma gente de armas", para transferir as relíquias para a catedral, centro religioso do espaço lisboeta. O facto de ser o deão da Sé a conduzi-las, e não o bispo, é também estranho, parecendo estar associado à ausência de Álvaro, o sucessor de Gilberto de Hastings na cátedra episcopal, talvez devido a um conflito não muito claro com o cabido ${ }^{25}$. Seja qual for a razão, tudo indica que a chegada das relíquias vicentinas não era aguardada e, portanto, também não teria sido decidida pelo rei ou pelos seus máximos representantes eclesiásticos e militares.

Acima de tudo, a sensação de improviso que rodeia o episódio acaba por mostrar a relativa falta de autoridade da Sé sobre a paróquia de Santa Justa, e portanto sobre a comunidade moçárabe, uma vez que o deão tem de negociar a transferência das relíquias "prudentemente, para que a movimentação popular não degenere em tumulto”. Não só o conflito entre os diversos grupos envolvidos parece iminente, como, para chegar à catedral, as relíquias têm que passar pelos bairros onde a presença moçárabe é provavelmente mais forte. Trazidas para o arrabalde ocidental, na ribeira do Tejo, através do profundo esteiro que só no fim da Idade Média virá a assorear-se, teriam seguramente de entrar na cidade por uma das portas da muralha que se abriam a ocidente. Era uma zona menos nobre, densamente povoada por artesãos e pescadores, que o poder deixava geralmente às minorias. Em 1147, o cruzado que escreve a célebre narrativa da conquista de Lisboa diz que "os arrabaldes ficam albergados sob as muralhas, a modo de bairros recortados nas rochas, de tal forma que cada bairro se

\footnotetext{
${ }^{24}$ José Mattoso (ed.), Portugaliae Monumenta Historica, Nova Série, II/1, Livro de linhagens do Conde D. Pedro, Lisboa, Academia das Ciências, 1980, XXI G6. Sobre Gonçalo Mendes da Maia, ver José Mattoso, Ricos-homens, infanções e cavaleiros, pp. 48, 85, 102, 141, 165 e 237.

${ }^{25}$ Maria João Branco, "Reis, bispos e cabidos: a diocese de Lisboa durante o primeiro século da sua restauração" in Lusitania Sacra, $2^{\text {a }}$ série, t. X, 1998, pp. 64-67.
} 
toma por castelo bem fortificado, tais são os obstáculos de que está rodeado"26. Apesar do tom exageradamente bélico da descrição, que deve ser lida à luz do primeiro contacto do seu autor com uma praça que iria cercar durante os três meses seguintes, é provável que esta morfologia cerrada dos subúrbios lisboetas se mantivesse em 1173. Uma óbvia ameaça ao êxito da trasladação dos restos vicentinos de fora para dentro da cidade, que a escolta armada, mesmo discreta (“alguma gente de armas”), procura assegurar.

Este exemplo de conflito religioso entre centro e periferia tinha, como vimos, raízes na tentativa de aculturação gregoriana levada a cabo pelos conquistadores. A trasladação de São Vicente veio exacerbá-lo. Na verdade, sabemos por um cânone sinodal de 1240 que os moçárabes ainda não tinham aceitado pacificamente a perda das relíquias quase três quartos de século volvidos, pois o bispo ordena a todos os fiéis da diocese a peregrinação anual obrigatória à Sé para as venerar ${ }^{27}$. Sabemos também que 16 de Setembro, aniversário da trasladação, era o único dia do ano em que o rito moçárabe se podia celebrar na Sé, exotismo que sobreviveu até à reforma litúrgica do Concílio Vaticano II e que não pode deixar de relacionar-se com a intenção de aí atrair a comunidade que o praticava ${ }^{28}$. Como diz enfaticamente José Luís de Matos, “a Sé pode ter arrebatado as relíquias, mas os moçárabes só lá iam nos velhos tempos desde que o culto fosse feito nos termos que eram os seus." 29

Daí que o relato dos Miracula sinta a necessidade de concluir que a trasladação acaba por fazer-se de "forma piedosa e festiva (...) acompanhada por toda a cidade em veneração e com cânticos de louvor a Deus. "É uma forma de sublinhar o consensus ideal em torno da chegada do santo, um consenso que, no entanto, está muito longe de verificar-se na prática.

O clima de tensão político-religiosa latente no texto torna-se, no entanto, precioso aos olhos do historiador porque permite trazer ao de cima aspectos silenciados da vida social que de outra forma não notaríamos. Assim nos surgem, como em palimpsesto, as

\footnotetext{
26 "De Expugnatione Lyxbonensi" in Nascimento, A conquista de Lisboa aos mouros, p. 79.

27 António Garcia y Garcia (ed.), Synodicon Hispanicum. II. Portugal, Madrid, Biblioteca de Autores Cristianos, 1982, p. 293.

${ }_{28}$ José Falcão, O mártir S. Vicente e a Sua Liturgia, Lisboa, Câmara Municipal de Lisboa, 1974, pp. 5-18.

${ }^{29}$ José Luís de Matos, Lisboa islâmica, p. 36.
} 
relações de força entre as diversas comunidades, os espaços físicos hierarquizados que elas ocupavam na topografia lisboeta e até os vários modos de apropriação colectiva do culto de São Vicente.

É possível reconhecer o bairro dos colonos do Norte peninsular em torno do castelo e da igreja de Santiago, no alto da cidade, o dos ingleses e franceses na zona da catedral e da igreja da Madalena, a meia encosta, e a comunidade do mosteiro de S. Vicente de Fora, inicialmente constituída por cruzados e frades germânicos, nos arrabaldes a leste da muralha, exactamente no extremo oposto ao da provável moçarabia, a oeste, entre Santa Maria de Alcamim e Santa Justa.

Na Lisboa da segunda metade do século XII, todas estas comunidades veneravam São Vicente, mas um São Vicente diferente. Todas tinham a sua própria "estética da recepção", para usar o conceito célebre de Hans-Robert Jauss ${ }^{30}$, do grande mártir hispano-romano. Para os moçárabes, ele era um símbolo de resistência ao novo poder vindo do norte. Para os cristãos portugueses e "francos", era um símbolo do domínio sobre o sul conquistado. Um dos sinais mais claros da assimilação da identidade moçárabe pela nova cultura dominante em Lisboa será justamente a conversão de São Vicente em padroeiro do concelho e da diocese. Uma assimilação que começa às primeiras horas de 16 de Setembro de 1173, longínqua manhã em que os paroquianos da igreja de Santa Justa perdem a posse física das relíquias vicentinas para o cabido da catedral.

\footnotetext{
${ }^{30}$ Hans Robert Jauss, Pour une esthetique de la reception, Paris, Gallimard, 1990.
} 